\title{
Optimization of the basic formulation of a traditional baked cassava cake using response surface methodology
}

\begin{abstract}
The optimum formulation for production of a Malaysian traditional baked cassava cake was determined using response surface methodology (RSM). Effects of amount of ingredients such as sugar (10-30\%) and coconut milk (15-35\%) on the textural characteristics (hardness and chewiness) and sensory qualities (colour, firmness, cassava flavour and overall acceptability) of cakes were investigated. Significant regression models which explained the effects of different percentages of sugar and coconut milk on all response variables were determined. The coefficients of determination, $\mathrm{R} 2$ of all the response variables were higher than 0.8. Based on the response surface and superimposed plots, the basic formulation for production of Malaysian traditional baked cassava cake with desired sensory quality was obtained by incorporating with $25 \%$ of sugar and $20 \%$ of coconut milk.
\end{abstract}

Keyword: Cassava, Basic formulation, Response surface methodology, Baked cassava cake 